\title{
Supporting Information for: Secondary organic aerosol formation from biomass burning emissions
}

Christopher Y. Lim, David H. Hagan, Christopher C. Cappa, Matthew M. Coggon, Abigail R. Koss, Kanako Sekimoto, Joost de Gouw, Carsten Warneke, Jesse H. Kroll

\section{T1. Initial PM composition}

\begin{tabular}{|c|c|c|c|c|c|c|c|c|c|c|}
\hline \multirow[b]{2}{*}{ Fire } & \multirow[b]{2}{*}{ Fuel } & \multirow[b]{2}{*}{$\begin{array}{l}\text { Included in } \\
\text { analysis? }\end{array}$} & \multirow[b]{2}{*}{$\begin{array}{r}\text { Sampling } \\
\text { time }(\mathrm{min})\end{array}$} & \multicolumn{2}{|c|}{$\begin{array}{l}\text { Initial gas phase } \\
\text { composition }\end{array}$} & \multicolumn{5}{|c|}{ Initial particle phase composition } \\
\hline & & & & $\begin{array}{r}\text { NMOGs } \\
(p p b)\end{array}$ & $\begin{array}{r}\mathrm{NMOG} \\
\left(\mu \mathrm{g} \mathrm{Cm}^{-3}\right)\end{array}$ & $\begin{array}{r}\text { POA } \\
\left(\mu \mathrm{g} \mathrm{m}^{-3}\right)\end{array}$ & $\begin{array}{r}\mathrm{BC} \\
(\mu \mathrm{g} \mathrm{m}-3)\end{array}$ & Org/rBC & $0 / c$ & $H / C$ \\
\hline Fire08 & Engelmann spruce(PIEN) & Yes & 15.00 & 250.06 & 369.75 & 51.80 & 0.76 & 216.00 & 0.33 & 1.79 \\
\hline Fire21 & lodgepole pine (PICO) - Litter & Yes & 11.32 & 167.14 & 261.53 & 28.83 & 2.29 & 33.89 & 0.25 & 1.84 \\
\hline Fire23 & $\begin{array}{l}\text { Subalpine fir (ABLA), Fish Lake - } \\
\text { Canopy }\end{array}$ & No & 5.13 & 183.49 & 263.15 & 9.66 & 18.36 & 1.41 & 0.45 & 1.70 \\
\hline Fire25 & Engelmann spruce (PIEN) - Canopy & Yes & 5.70 & 113.52 & 172.47 & 9.66 & 2.75 & 11.78 & 0.34 & 1.80 \\
\hline Fire26 & Engelmann spruce (PIEN) - Duff & Yes & 20.53 & 295.42 & 397.01 & 20.14 & 0.00 & 1300.93 & 0.20 & 1.86 \\
\hline Fire28 & $\begin{array}{l}\text { chaparral (manzanita) - } \\
\text { Uncontaminated (M-NM), Canopy }\end{array}$ & Yes & 7.28 & 456.18 & 680.61 & 46.14 & 24.00 & 4.91 & 0.27 & 1.79 \\
\hline Fire29 & $\begin{array}{l}\text { chaparral (chamise) - Contaminated } \\
\text { (C-SD), Canopy }\end{array}$ & No & 3.68 & 239.44 & 287.26 & 16.92 & 39.98 & 1.42 & 0.46 & 1.73 \\
\hline Fire30 & $\begin{array}{l}\text { chaparral (manzanita) - } \\
\text { Contaminated (M-SD), Canopy }\end{array}$ & Yes & 9.03 & 797.37 & 1055.01 & 68.13 & 43.74 & 5.15 & 0.32 & 1.75 \\
\hline Fire31 & Douglas-fir (PSME), Rotten Log & Yes & 18.95 & 768.22 & 1078.06 & 152.92 & 0.04 & 2836.27 & 0.60 & 1.79 \\
\hline Fire32 & $\begin{array}{l}\text { chaparral (chamise) - } \\
\text { Uncontaminated (C-NM), Canopy }\end{array}$ & No & 7.07 & 432.51 & 508.05 & 25.77 & 36.85 & 2.09 & 0.40 & 1.75 \\
\hline Fire33 & $\begin{array}{l}\text { chaparral (manzanita) - } \\
\text { Contaminated (M-SD), Canopy }\end{array}$ & Yes & 12.70 & 666.90 & 839.08 & 54.33 & 30.04 & 5.19 & 0.31 & 1.77 \\
\hline Fire38 & ponderosa pine (PIPO) - Litter & Yes & 7.70 & 196.89 & 297.53 & 19.12 & 5.00 & 8.16 & 0.34 & 1.78 \\
\hline Fire39 & ponderosa pine (PIPO) - Canopy & Yes & 13.02 & 635.94 & 1035.87 & 139.41 & 5.82 & 97.92 & 0.31 & 1.75 \\
\hline Fire41 & lodgepole (PICO) - Litter & Yes & 9.65 & 151.83 & 251.55 & 14.55 & 0.36 & 94.86 & 0.38 & 1.76 \\
\hline Fire43 & Douglas-fir (PSME) - Litter & No & 7.78 & 104.67 & 178.01 & 3.41 & 7.91 & 0.92 & 0.42 & 1.61 \\
\hline Fire46 & $\begin{array}{l}\text { chaparral (chamise) - Contaminated } \\
\text { (C-SD), Canopy }\end{array}$ & No & 8.22 & 246.90 & 347.08 & 13.89 & 32.64 & 1.26 & 0.50 & 1.68 \\
\hline Fire49 & Excelsior & No & 3.47 & 230.94 & 345.55 & 14.47 & 30.17 & 1.08 & 0.58 & 1.71 \\
\hline Fire50 & Dung & Yes & 19.50 & 955.79 & 1293.72 & 200.81 & 0.77 & 620.45 & 0.21 & 1.84 \\
\hline Fire51 & Subalpine fir (ABLA), Fish Lake - Litter & No & 9.97 & 158.29 & 284.58 & 9.07 & 10.87 & 1.47 & 0.26 & 1.78 \\
\hline Fire52 & Engelmann spruce (PIEN) & Yes & 16.90 & 227.36 & 331.91 & 24.82 & 4.14 & 17.86 & 0.38 & 1.73 \\
\hline Fire53 & loblolly pine (PITA) - Litter & Yes & 12.87 & 265.07 & 461.89 & 41.58 & 9.39 & 11.14 & 0.33 & 1.78 \\
\hline Fire56 & Subalpine fir (ABLA), Fish Lake - Duff & Yes & 16.12 & 632.51 & 927.77 & 28.70 & 0.02 & 1416.60 & 0.24 & 1.80 \\
\hline Fire57 & Douglas-fir (PSME) & Yes & 15.63 & 445.64 & 651.54 & 68.33 & 8.09 & 23.29 & 0.44 & 1.74 \\
\hline Fire61 & Excelsior & Yes & 7.47 & 480.06 & 687.78 & 33.90 & 26.87 & 3.46 & 0.52 & 1.73 \\
\hline Fire62 & Bear Grass & Yes & 14.25 & 546.89 & 771.58 & 67.12 & 3.93 & 115.32 & 0.32 & 1.74 \\
\hline Fire63 & lodgepole (PICO) & Yes* & 14.77 & 590.09 & 883.59 & 96.97 & 9.57 & 41.41 & 0.37 & 1.75 \\
\hline Fire64 & Douglas-fir (PSME) - Canopy & Yes & 11.93 & 1139.78 & 1731.36 & 194.96 & 6.04 & 212.28 & 0.37 & 1.72 \\
\hline Fire66 & Sage & Yes & 6.38 & 502.32 & 715.94 & 37.72 & 7.19 & 23.49 & 0.38 & 1.73 \\
\hline
\end{tabular}

Table T1. Initial conditions in chamber for all PTR-ToF-MS and AMS measured experiments before start of oxidation. Fire 63 is a dark, control experiment (no oxidation). Fires with initial Org $/ \mathrm{rBC}<3.4$ were excluded from the analysis presented in the paper due to enhanced wall loss from $254 \mathrm{~nm}$ light (see main text, Sect. 3.1). 


\section{T2. SOA carbon yields}

\begin{tabular}{|r|r|r|r|}
\hline & \multicolumn{2}{|c|}{ CE corrected } & CE = 1 \\
\hline Days & Yield & Standard error $\mathbf{( 1 \sigma})$ & Yield \\
\hline 0.25 & 0.24 & 0.04 & 0.04 \\
\hline 0.5 & 0.32 & 0.05 & 0.07 \\
\hline 1 & 0.38 & 0.06 & 0.09 \\
\hline 2 & 0.44 & 0.09 & 0.10 \\
\hline 3 & 0.51 & 0.09 & 0.12 \\
\hline 4 & 0.56 & 0.09 & 0.14 \\
\hline
\end{tabular}

Table T2. Table of SOA carbon yields from NMOG carbon reacted using CE correction presented in the text and assuming a constant $\mathrm{CE}$ equal to 1 . NMOG carbon reacted is calculated based on initial NMOG concentration, OH exposure, and an average $\mathrm{OH}$ reaction rate constant based on identified NMOGs.

\section{S1. Experimental setup}

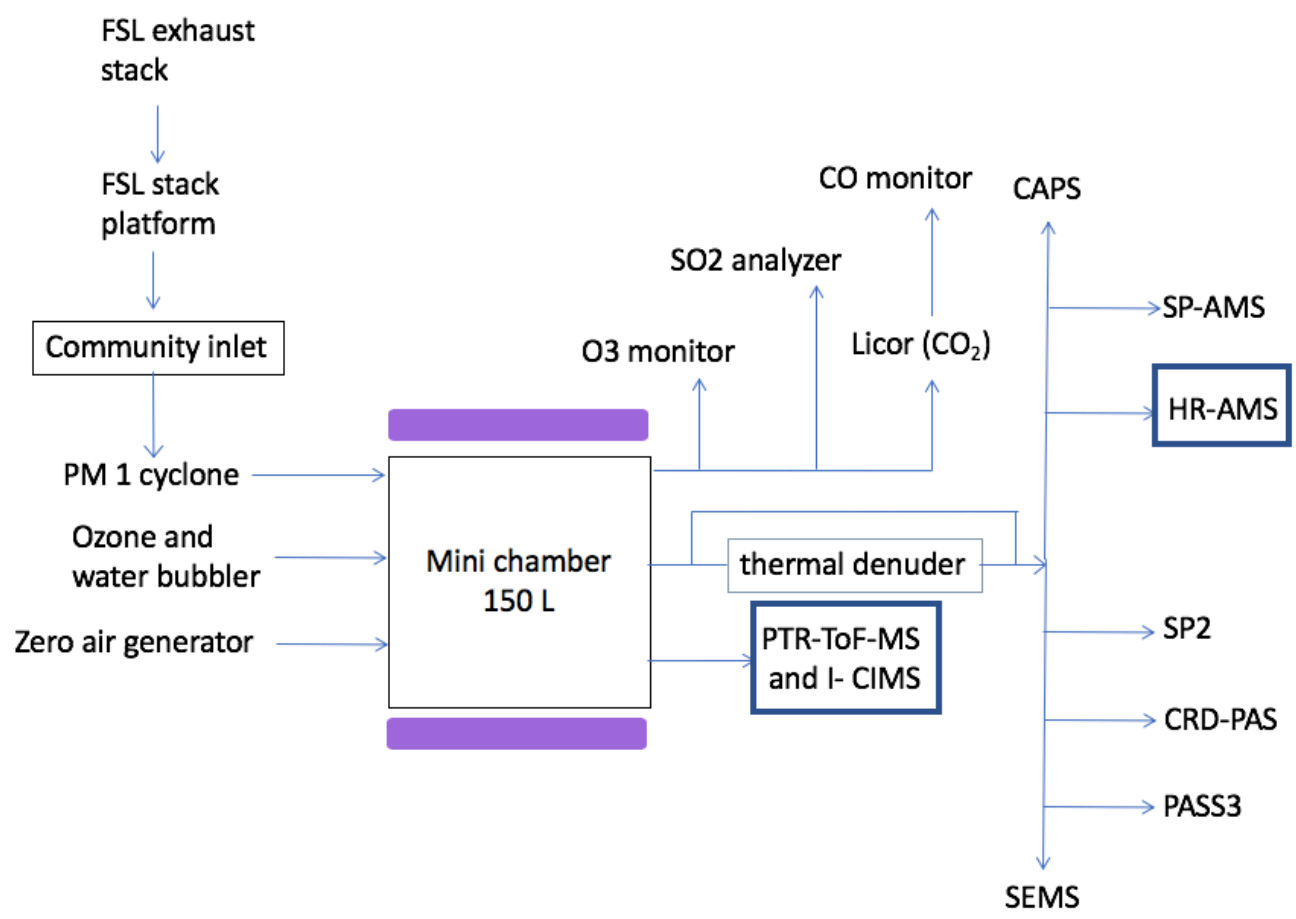

Figure S1. Experimental setup. Emissions from fires entered the exhaust stack and were drawn through a community inlet to the mini-chamber. Chamber was run in semi-batch mode. Full suite of instruments is shown. 


\section{S2. Comparison between stack and chamber}

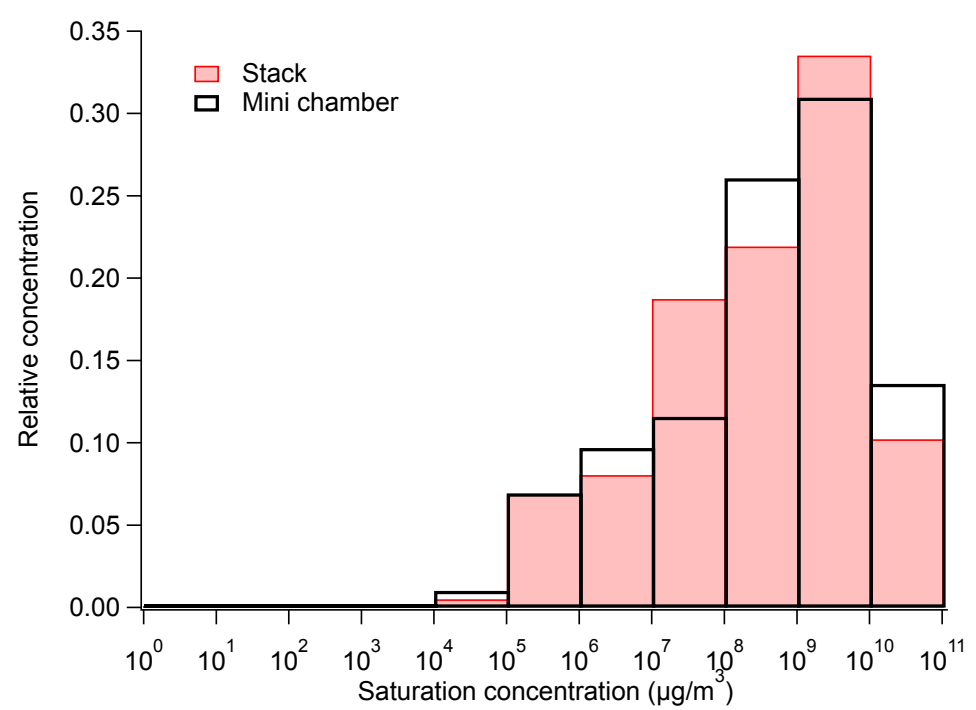

Figure S2. Comparison of volatility distributions for gas phase compounds measured in the mini chamber (black) and measured directly from the FSL stack in red (Koss et al., 2017). Distribution of compounds measured is roughly the same indicating that vapor losses from the community inlet or other transfer lines did not significantly affect the mixture of gas phase compounds entering the mini chamber.

\section{S3. Collection efficiency parameterization}

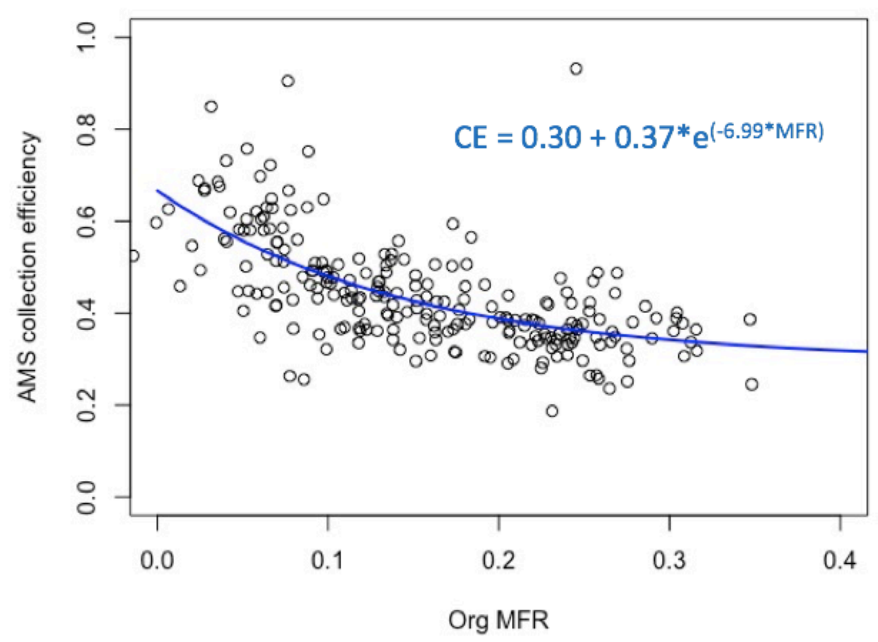

Figure S3. Calculated AMS collection efficiency vs. Org MFR (mass fraction remaining after passing through thermal denuder). Blue exponential fit ( $\left.\mathrm{CE}_{\text {best }}\right)$ was used to parameterize AMS collection efficiency correction for all data points. Red exponential fit $\left(\mathrm{CE}_{\max }\right)$ was used to constrain the range of reasonable carbon yields in Fig. 6. 


\section{S4. OA wall loss fit}

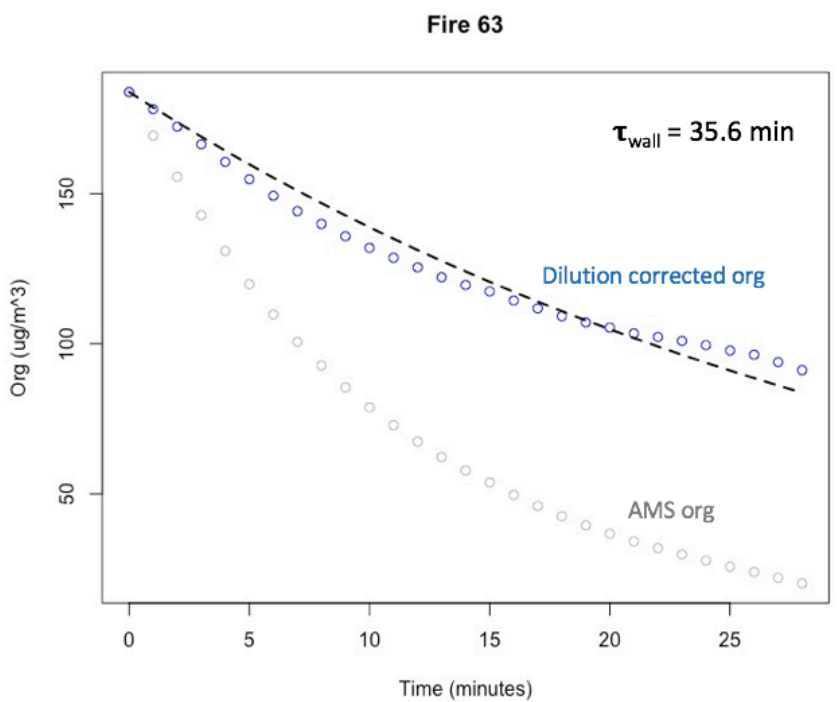

Figure S4. Wall loss fit for dark experiment (Fire 63). Wall loss time constant equals 35 minutes, based on fit of dilution corrected OA mass.

\section{S5. Dilution corrected primary IVOCs}

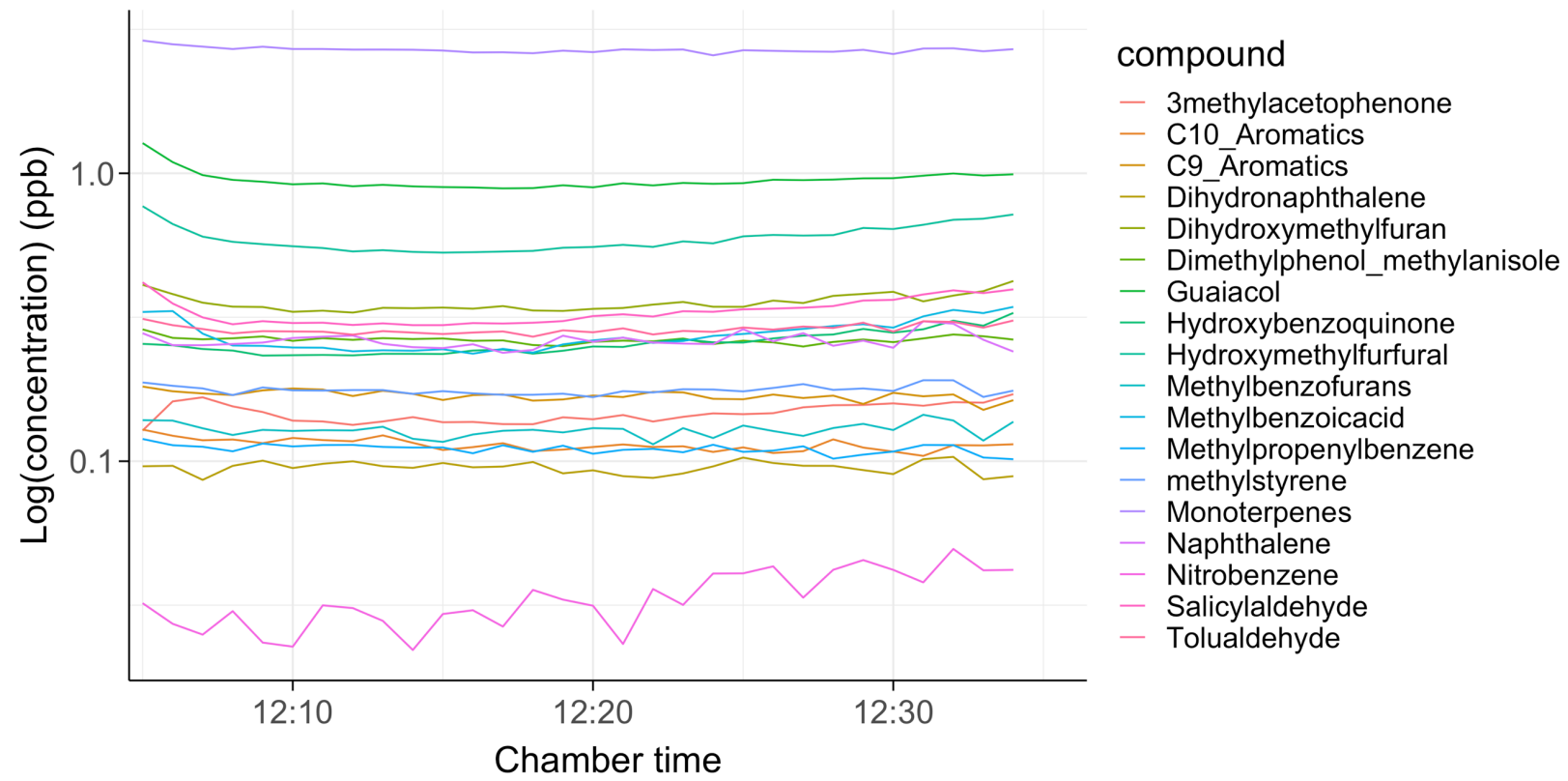

Figure S5. Time series for dilution-corrected, high molecular weight gas phase compounds measured by PTR-ToF-MS. Dilution corrected concentrations are stable, indicating the impact of vapor wall loss for these compounds is not important. 


\section{S6. Comparison between previous FSL aging studies}
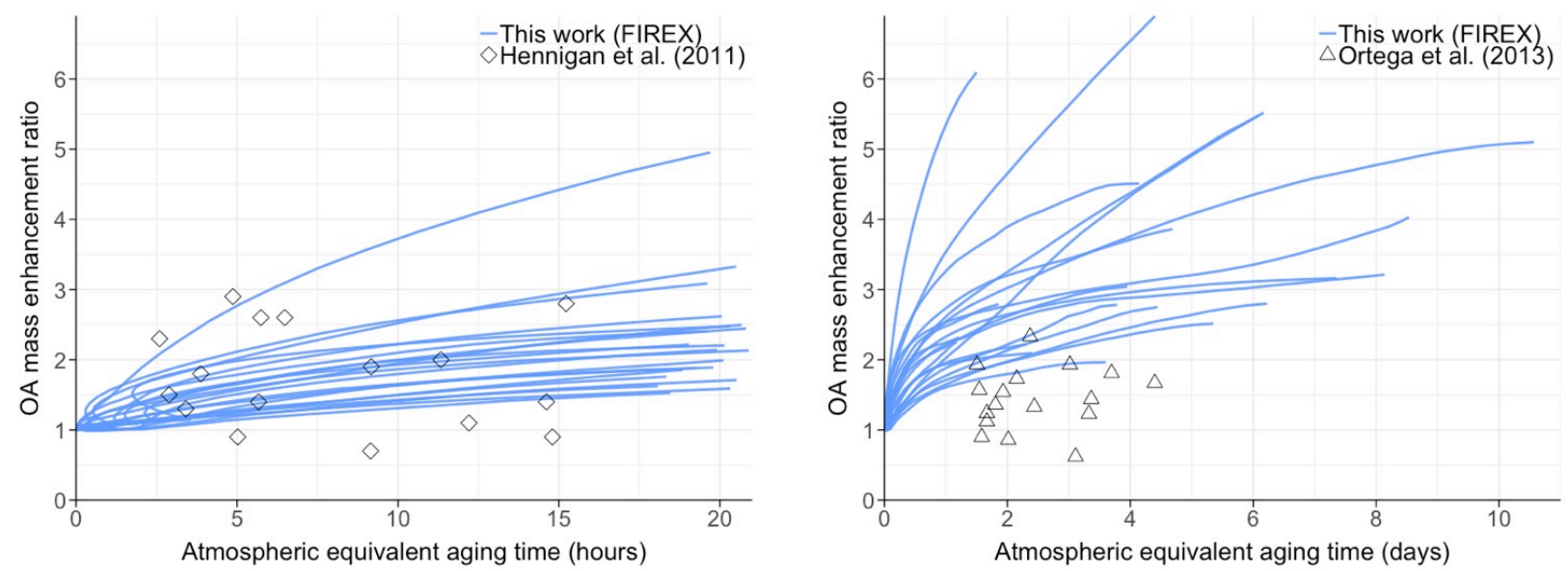

Figure S6. Comparison between OA enhancement ratios for this work and previous Fire Lab aging studies. Panel on left is comparison to room-burn, large chamber oxidation from Hennigan et al. (2011). Recent work from Ahern et al. (2019) is also roughly consistent with this, but includes an internal CE correction. Panel on right is comparison to room-burn, flow tube oxidation from Ortega et al. (2013). Data are not corrected for AMS collection efficiency in order to compare with published work (CE = 1).

\section{S7. OA enhancement ratio scatterplots}
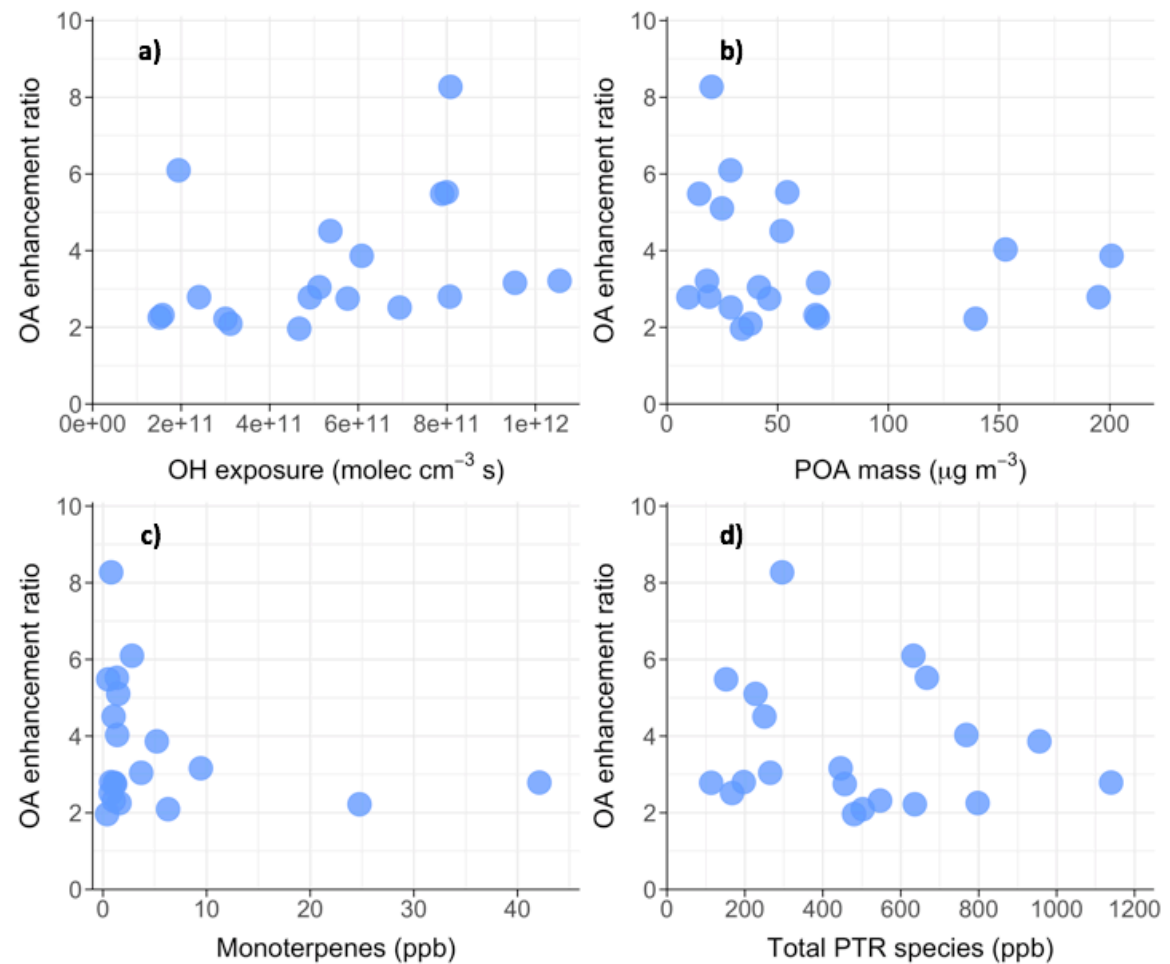

Figure S7. Scatterplots of OA enhancement ratio vs. various parameters: (a) OH exposure, (b) POA mass, (c) monoterpene concentration, (d) total PTR species. No single parameter shows a strong relationship with OA enhancement ratio. 


\section{S8. Effect of aerosol loading on carbon yield}

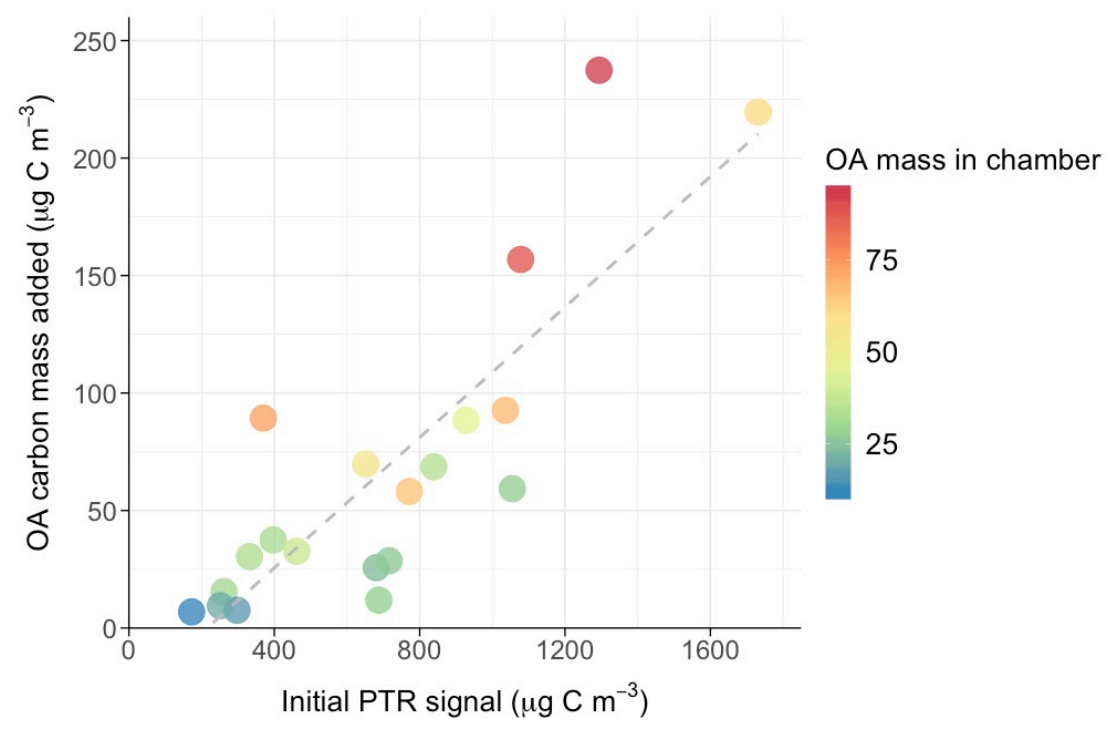

Figure S8. OA carbon mass added as a function of initial PTR signal and colored by OA mass in suspended in the chamber (1 day of equivalent exposure). Higher aerosol mass in the chamber contributes to higher conversion of gas-phase carbon to SOA.

\section{S9. POA vs. SOA scatterplots}
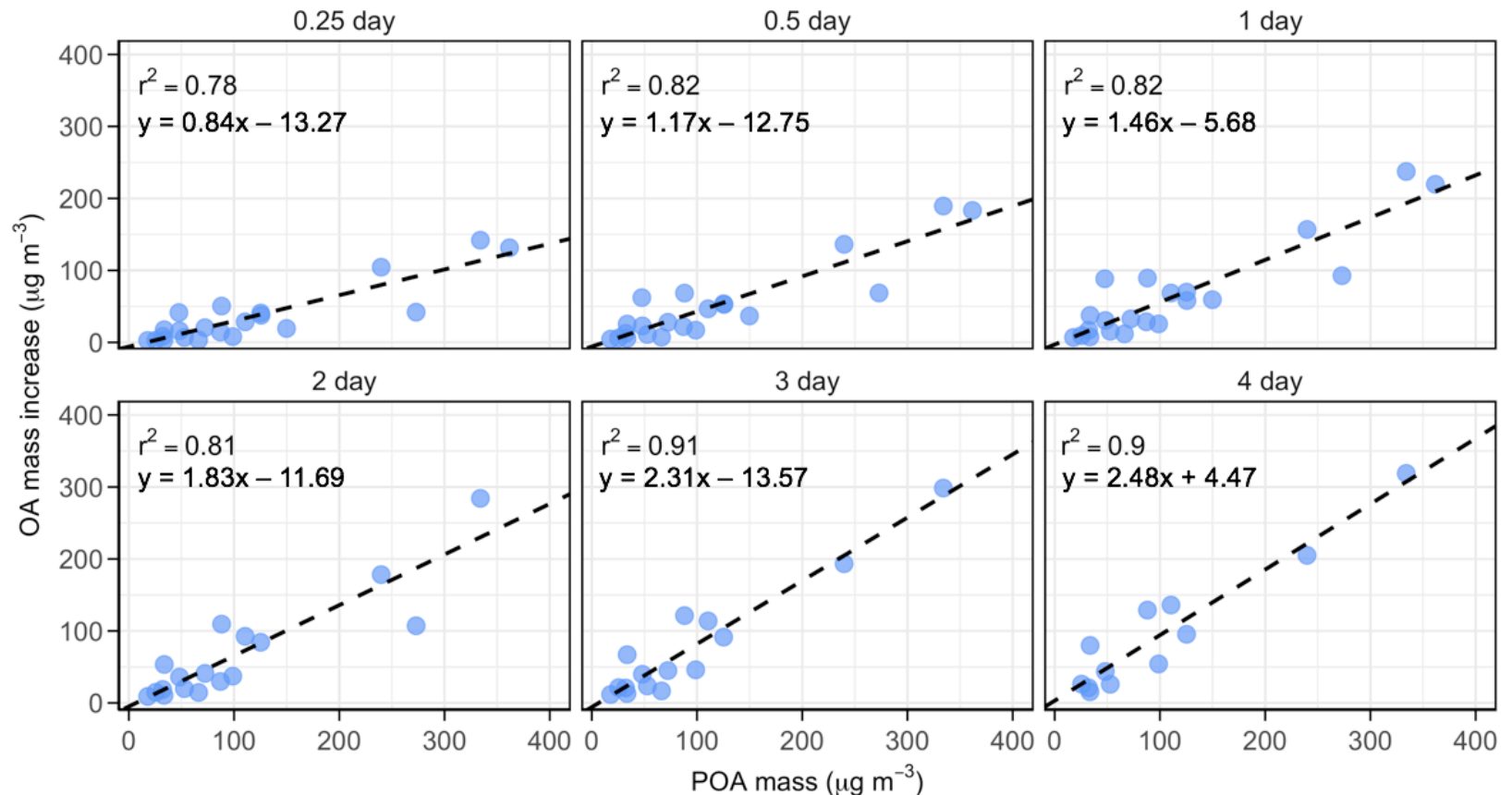

Figure S9. Scatterplots of SOA mass vs. POA mass at $\mathrm{OH}$ exposures equivalent to 0.25 days of atmospheric aging to 4 days of aging. Dashed lines are linear regressions described by the fit equations. 